\title{
Percutaneous Radiofrequency Ablation through a Subtalar Approach in Osteoid Osteoma of the Calcaneus
}

\author{
by Ramos-Pascua L.R., Ph.D ${ }^{1 凶}$, Santos-Martín G., MD ${ }^{2 \rrbracket}$, Fernández-Hernández O., MD $^{3 凶}$, \\ Sántos-Sánchez J.A., Ph.D ${ }^{4}$, Sánchez-Herráez S., Ph. $\mathrm{D}^{5}$
}

The occurrence of osteoid osteomas of the foot is rare and their treatment has usually been surgical. A 13 yearold male with a subchondral osteoid osteoma in the right calcaneus was treated with percutaneous radiofrequency ablation using a simple subtalar approach. Two years later there was no evidence of recurrence and he remains free of pain with normal function.

The Foot and Ankle Online Journal 4 (5): 2

Key words: Osteoid Osteoma, calcaneus, bone tumor.

Published: May, 2011

This is an Open Access article distributed under the terms of the Creative Commons Attribution License. It permits unrestricted use, distribution, and reproduction in any medium, provided the original work is properly cited. (The Foot and Ankle Online Journal (www.faoj.org), 2011 All rights reserved.

$\mathrm{O}$ steoid osteoma is a small benign osteoblastic tumor which causes localized pain. It accounts for approximately $11 \%$ of all benign bone tumors. It usually occurs in children and young adults and most commonly in the cortex of the shaft of long bones. Its treatment has been indicated to lighten the symptomatology and to avoid the possibility of disorders in the nearby growth cartilage, chronic changes of bone remodeling and osteoarthritis, according to the case.

Address correspondence to: Luis Rafael Ramos-Pascua. Complejo Hospitalario Universitario de León. Altos de Nava s/n, 24071, León, Spain. Email: luisramospascua@gmail.com

${ }^{1}$ Head of Orthopedic Surgery Department, at the University Hospital of León (Spain).

2 Assistant Doctor. Department of Radiology. University Hospital of Salamanca. Spain.

${ }^{3}$ Assistant Doctor. Department of Orthopaedic Surgery. University Hospital of León. Spain.

4 Assistant Doctor. Department of Radiology. University Hospital of Salamanca. Spain.

5 Assistant Doctor. Department of Orthopedic Surgery. University Hospital of León. Spain.
The therapeutic methods of an osteoid osteoma currently available include medical treatment, bloody approach with intralesional or wide resection of the nidus, and percutaneous techniques. ${ }^{1}$ These can be divided into two groups: those that try to remove the lesion physically (by curettage or milling). ${ }^{2-4}$ and those that seek their destruction in-situ (ablation). The ablative techniques include the injection of ethanol, laser photocoagulation ${ }^{5}$ and radiofrequency. ${ }^{6-8}$

The percutaneous procedures eliminate selectively the pathologic tumoral tissue, reducing the pathological fractures morbidity and its prevention. They are technically simple, provide immediate analgesia ${ }^{2-3}$ and add the advantage of a lower cost to the health system. In addition, they allow the use of the computerized tomography (CT) scan to exactly locate the nidus and can be done with local anesthesia, even on an outpatient basis, allowing immediate loading without any external support and a quick return to their occupations. ${ }^{2}$ 


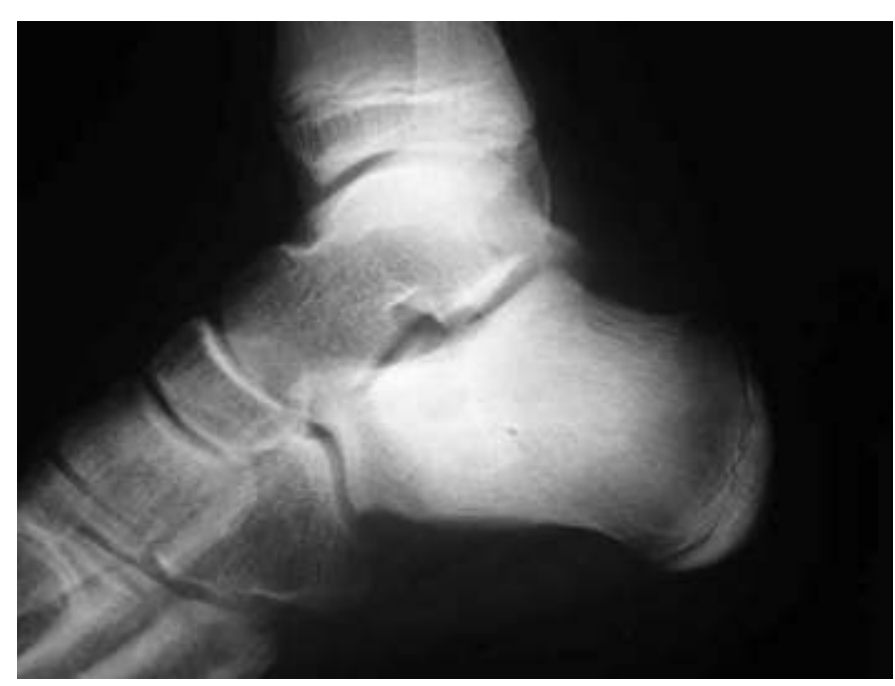

Figure 1 Lateral radiograph of the right foot showing sclerosis at the subchondral area of the calcaneus.

All of these advantages are more evident in those cases located in poorly accessible areas, which would need wide and difficult approaches. The main disadvantage is the lack of histological confirmation in almost half of the cases. ${ }^{1} \quad$ Calcaneal osteoid osteoma is extremely rare and it has usually been treated by surgical excision. Percutaneous radiofrequency ablation (RF) in the calcaneus has been previously described as being exceptional. ${ }^{9}$

\section{Case Report}

A 13 year-old male presented with an 18-month history of pain and swelling in the right hindfoot and ankle. There was no history of trauma. Initially, the pain was intermittent in the morning. In the final six months, the pain became constant and more severe at night. It was relieved by Ibuprofen.

On examination, there was tenderness and swelling around the lateral aspect of the hindfoot. No erythema or heat was present. He showed full range of motion of the ankle joint and mild stiffness of the subtalar joint, with mild discomfort at the end of the range of motion.

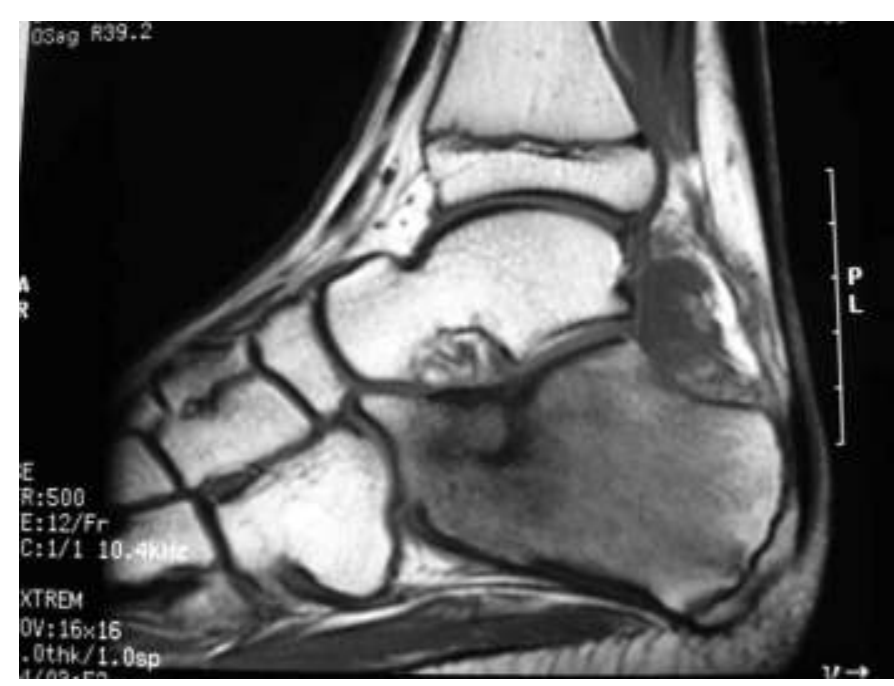

Figure 2 Sagittal T1-weighted MRI shows the nidus as a well-circumscribed area of low-signal intensity in the calcaneus with bone sclerosis and edema in the surrounding bone medulla.

The right calf muscles were atrophied compared with those of the left calf. There were no neurovascular deficits. Laboratory data were normal.

Plain radiographs of the ankle showed a sclerotic area in the calcaneus just below to the subtalar joint. (Fig. 1) Radionuclide bone scan revealed a focal uptake in this area. A magnetic resonance image (MRI) showed a well-circumscribed area of low-signal intensity in the anterolateral aspect of the right calcaneus adjacent to the posterior talocalcaneal joint with surrounding edema.(Fig. 2) CT scan confirmed the presence of a small osteolytic lesion with a sclerotic rim in the same place. (Fig. 3) An osteoid osteoma was diagnosed using these data.

After a regional anesthetic, the patient was placed on the CT imaging table in a supine position with internal rotation of the leg. (Fig. 4) Under CT guidance, a Kirschner wire with an outer diameter of $1.5 \mathrm{~mm}$ was placed in the center of the lesion using a lateral subtalar approach. (Fig. 5) A cannula was placed over the wire; and the wire was replaced through the cannula by a TEW-STC straight electrode (Radionics $^{\mathrm{TM}}$, Burlington, Massachusetts). 


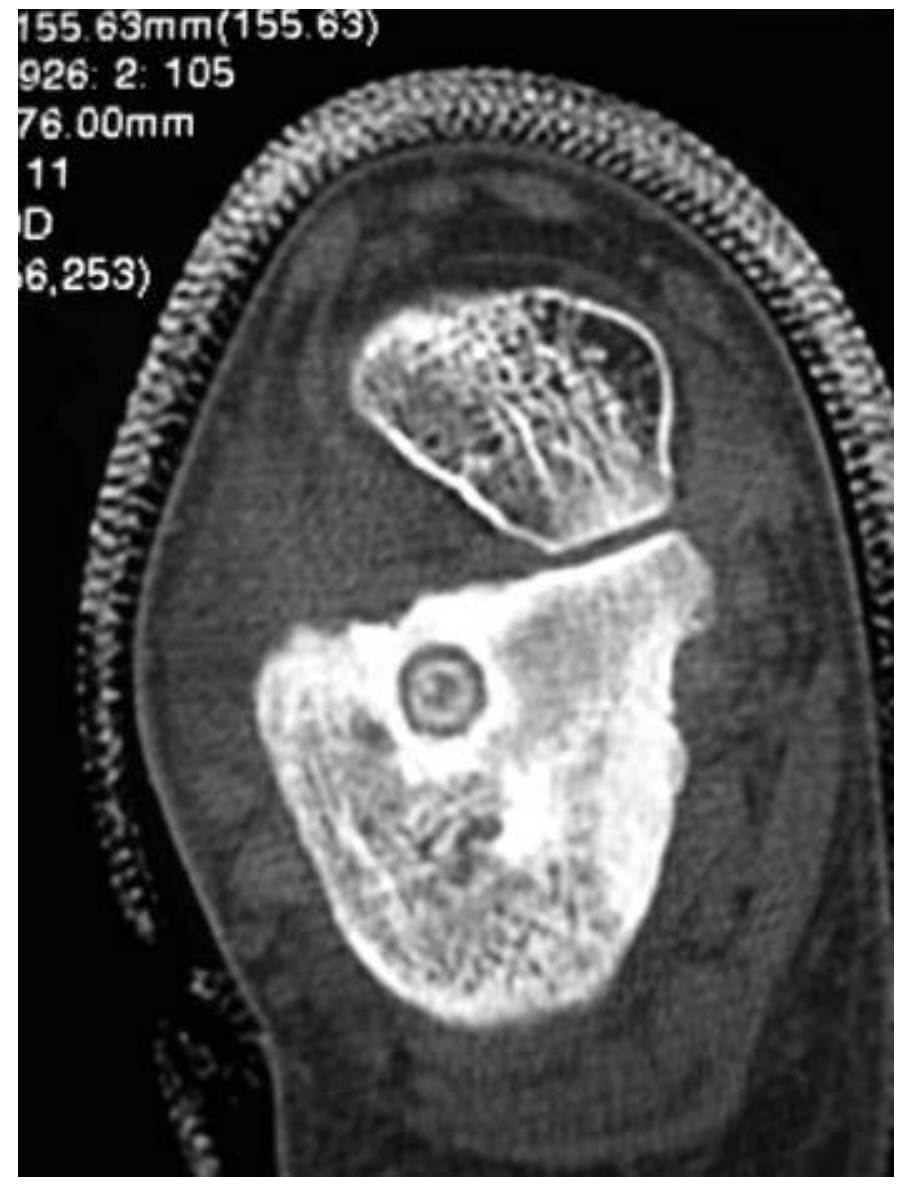

Figure 3 Coronal CT shows the nidus adjacent to the subtalar joint.

The electrode, insulated throughout the length except for the terminal $5 \mathrm{~mm}$, was heated to $90^{\circ} \mathrm{C}$ for 6 minutes with a radiofrequency generator (Radionics RFG-3CF). Since the diameter of the nidus was estimated in $12 \mathrm{~mm}$ in length, and the thermoablation occurs only in a sphere of tissue approximately $1 \mathrm{~cm}$ in diameter, the procedure was repeated changing the electrode a few millimetres to one side. Finally, the electrode and the cannula were removed and the small skin wound was closed with a steristrip. A specimen was not obtained for histology.

Without postoperative complications, the patient showed an immediate relief of pain. He was allowed to bear weight immediately after the procedure and he was completely free of pain by the fourth day. At a two year follow-up, there was no evidence of recurrence and the patient remained free of pain with normal activity.

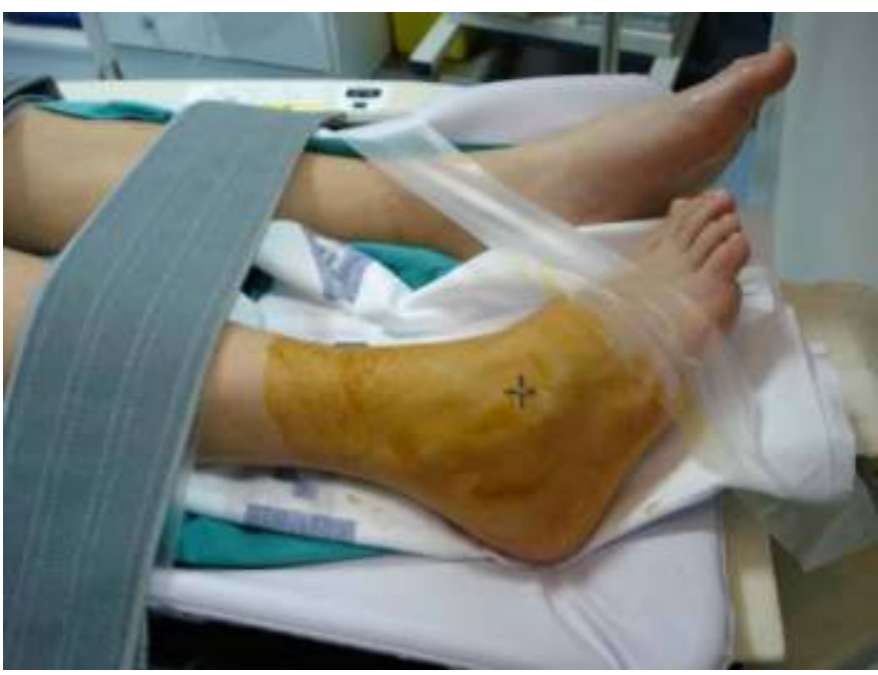

Figure 4 Appearance of the foot, with internal rotation of the leg. The entrance point for the thermoablation has been marked.

\section{Discussion}

Osteoid osteomas in the foot are rare: $4-8 \%{ }^{10}$ Most of them are located in the hindfoot, with $30 \%$ to $60 \%$ occurring in the talus, and $2 \%$ to $3 \%$ in the calcaneus. Calcaneal osteoid osteoma has not been described in literature very often, usually as case reports in juxtaarticular location. ${ }^{9-15}$

The juxta-articular subchondral location in the calcaneus could explain subtalar arthritis and mistaken or delayed diagnosis. ${ }^{13,15-17}$ Finally, a long delay in treatment may lead to muscle atrophies, growth disturbances, persistent joint stiffness or contractures. ${ }^{12-13}$ Thinking of the osteoid osteoma in a patient with a typical history of nocturnal pain relieved by NSAID medication, plus the imaging appearance of our case (although different from those of the more common cortical lesions) would be enough for the diagnosis. ${ }^{18}$ Although not all authors are of the same opinion ${ }^{19}$, we think that the biopsy is not necessary if there are no clinical or imaging doubts.

Even though there are cases of spontaneous healing after years of medical treatment with NSAIDs, surgical removal of the nidus is preferred to achieve rapid symptom relief. 


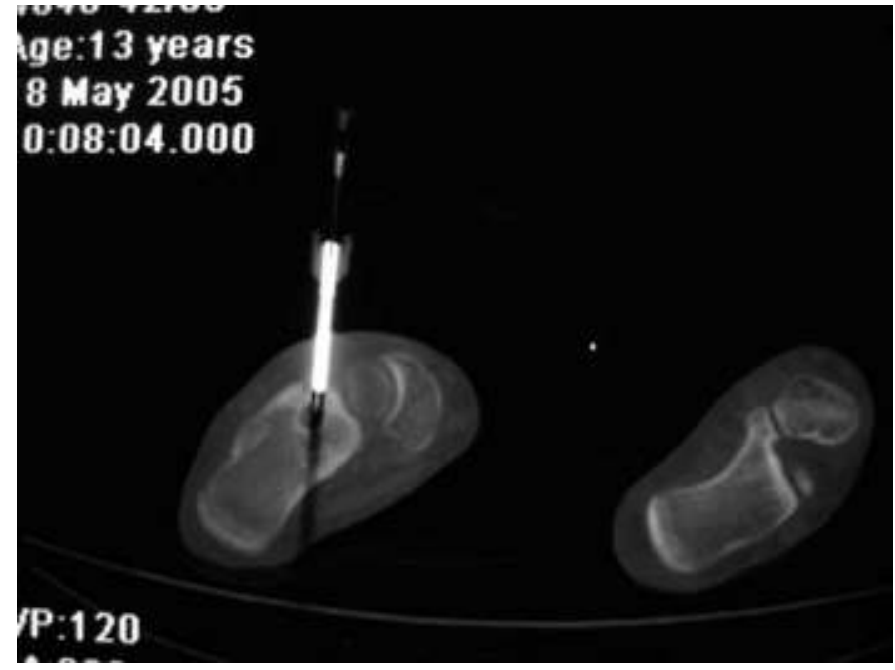

Figure 5 CT showing the radio-frequency electrode through the cannula in the center of the nidus.

However, the nidus is difficult to identify intraoperatively ${ }^{20}$, requiring an excessive amount of bone resection, which may result in weakening of the bony structure and an increased risk of fracture. Moreover, when osteoid osteoma is juxta-articular in location, as in our case, articular surface can be damaged by surgery. Most calcaneal osteoid osteomas reported in literature have been treated with en-bloc resection or curettage, usually packing the calcaneal defect with cancellous bone graft or hydroxyapatite. ${ }^{11-}$ 16,21 A short leg cast was always applied for some weeks postoperatively.

Percutaneous radiofrequency ablation (RF) is an alternative treatment to surgical excision in osteoid osteoma. The technique was introduced by Rosenthal, et al., ${ }^{7}$ in 1992, and it is at present recommended as the treatment of choice in most cases. ${ }^{22-23}$ The procedure causes thermal necrosis of a spherical area approximately $1 \mathrm{~cm}$ in diameter. For bigger lesions or when electrode placement is such that the entire tumor is not encompassed within one treatment, a second overlapping treatment can be given in the same session. ${ }^{23}$ It has a primary clinical success rates of between $73 \%$ to $95 \%$ with minimal complications, usually skin injuries, and reduced use of healthcare resources. ${ }^{7,24-25}$
To the best of our knowledge, isolated cases involving the foot have been previously reported ${ }^{26-27}$ and there are only a few specific reports on RF in osteoid osteoma of the calcaneus. ${ }^{9,25}$

Percutaneous radiofrequency ablation requires a small osseous access to allow insertion of the electrode. There is no bone loss and does not cause any significant structural weakening. This is particularly useful in calcaneal lesions, where the effects of the traditional surgery with an easy lateral subtalar approach could be avoided.

\section{Conclusion}

Percutaneous radiofrequency ablation of the nidus in osteoid osteomas has recently been introduced and offers advantages as compared with traditional open resection. In the calcaneus, the procedure could be performed on an outpatient basis and the patients can immediately resume all daily activities without cast, splints or other external supports. A larger series of calcaneal osteoid osteomas treated with radiofrequency ablation would be necessary to determine safety and efficacy.

\section{References}

1. Campanacci M, Ruggieri P, Gasbarrini A, Ferraro A, Campanacci L. Osteoid osteoma. Direct visual identification and intralesional excision of the nidus with minimal removal of bone. JBJS 81B:814-820, 1999.

2. Bühler M, Binkert C, Exner GU. Osteoid osteoma: technique of computed tomography-controlled percutaneous resection using standard equipment available in most orthopaedic operating rooms. Arch Orthop Trauma Surg 121:458-461, 2001. 3. Bühler M, Exner GU, Hodler J. CT-assisted percutaneous removal of an osteoid osteoma. Orthop Traumatol 3:159-65, 2001.

4. Ward WG, Eckardt JJ, Shayestehfar S, Mirra J, Grogan T, Oppenheim W. Osteoid osteoma diagnosis and management with low morbidity. Clin Orthop 291:229-235, 1993.

5. Cool P, Williams $\mathrm{DH}$, Pullicino V. Interstitial laser photocoagulation for the treatment of osteoid osteoma. JBJS 83B: 1125-1128, 2001. 
6. Tillotson CL, Rosenberg AR, Rosenthal DI. Controlled thermal injury of bone. Report of a percutaneous technique using radiofrequency electrode and generator. Invest Radiol 24: 888-892, 1989.

7. Rosenthal DI, Alexander A, Rosenberg AE, Springfield D. Ablation of osteoid osteomas with a percutaneously placed electrode: a new procedure. Radiology 183: 29-33, 1992.

8. Lindner NJ, Ozaki T, Roedl R, Gosheger G, Winkelmann W, Wörtler K. Percutaneous radiofrequency ablation in osteoid osteoma. JBJS 83B: 391-396, 2001.

9. Migues A, Velan O, Solari G, Pace G, Slullitel G, Santini E. Osteoid osteoma of the calcaneus: percutaneous radiofrequency ablation. J Foot Ankle Surg 44: 469-472, 2005.

10. De Palma L, Greco F, Coletti V. Osteoid osteoma of the foot. Arch Putti Chir Organi Mov 38: 113-122, 1990.

11.- Birdsall PD. Osteoid osteoma: an unusual cause of foot pain. Orthopedics 24: 173-174, 2001.

12. Christodoulou A, Ploumis A, Karkavelas G, Terzidis I, Tsagias I. A rare case of juxtaarticular osteoid osteoma of the calcaneus initially misdiagnosed as juvenile chronic arthritis. Arthritis Rheum 48: 776-779, 2003.

13. Okuda R, Kinoshita M, Morikawa J, Jotoku T, Shima H, Abe M. Tibialis spastic varus foot caused by osteoid osteoma of the calcaneus. Clin Orthop 412: 149-152, 2003.

14. Piatkowski S, Warda E. L'ostéome ostéoïde localisé au niveau du calcanéum. Rev Chir Orthop. 59: 609-613, 1973.

15. Sanhudo JAV. Osteoid osteoma of the calcaneus mimicking os trigonum syndrome: a case report. Foot Ankle Int 27: 548551, 2006.

16. Morris GB, Goldman FD. Osteoid osteoma causing subtalar joint arthralgia: a case report. J Foot Ankle Surg. 42: 90-94, 2003. 17. Pikoulas C, Mantzikopoulos G, Thanos L, Passomenos D, Dalamarinis C, Glampedaki-Dagianta K. Unusually located osteoid osteomas. Eur J Radiol. 20: 120-125, 1995.

18. Rosenthal DI, Springfield DS, Gebhardt MC, Rosenberg, AE, Mankin HJ. Osteoid osteoma: percutaneous radio-frequency ablation. Radiology 197: 451-454, 1995.

19. Rosenthal DI, Hornicek FJ, Torriani M, Gebhardt MC, Mankin, HJ. Osteoid osteoma: percutaneous treatment with radiofrequency energy. Radiology 229: 171-175, 2003.

20. Rossi T, Levitsky K. Osteoid osteoma of the calcaneus: an unusual cause of hindfoot pain in an adolescent athlete. J Athl Train. 31: 71-73, 1996.

21. Khurana JS, Mayo-Smith W, Kattapuram SV. Subtalar arthralgia caused by juxtaarticular osteoid osteoma. Clin Orthop 252: 205-208, 1990.

22. Ghanem I. The management of osteoid osteoma: updates and controversies. Curr Opin Pediatr 18: 36-41, 2006.

23. Rosenthal, DI. Radiofrequency treatment. Orthop Clin North Am 37: 475-484, 2006.

24. Finstein JL, Hosalkar HS, Ogilvie CM, Lackman RD. An unusual complication of radiofrequency ablation treatment of osteoid osteoma. Clin Orthop 448: 248-251, 2006.
25. Mastrantuono D, Martorano D, Verna V, Manzini A, Faletti C. L'osteoma osteoide. Nostra esperienza nel trattamento mediante radiofrequenza (RF). Radiol Med 109: 220-228, 2005.

26. Ghanem I, Collet LM, Kharrat K, Samaha E, Deramon H, Mertl P, Dagher F. Percutaneous radiofrequency coagulation of osteoid osteoma in children and adolescents. J Pediatr Orthop 12B: 244-252, 2003.

27.Lindner NJ, Ozaki T, Roedl R, Gosheger G, Winkelmann W, Wortler K. Percutaneous radiofrequency ablation in osteoid osteoma. JBJS 83B: 391-396, 2001. 